widely recommended for students in Great Britain. Moreover, at the modest cost of the paper-back edition, it is well worth the money and can be recommended for the general public and for patients, even for nurses and students-indeed for all who are anxious to have some basic knowledge of the subject.

It is easy to criticise such a book. In the excellent historical summary, for example, the author misses the point as to the probable or possible evolution of venereal syphilis in Europe from pre-existing endemic syphilis. Also, while the black-and-white anatomical drawings by Audrey Besterman are a delight, as with most medical artists, her art sometimes overcomes reality and is least effective in the microscopical interpretations where the treponemes are too long and the trichomonads, each with an excessively long extended axostyle, have their anterior flagella so elegantly splayed that the whole resembles a flying ballet or a prize-winning flower-arrangement.

More important, however, is the question, while the non-judgmental attitude encompassing greater sexual freedom, both homosexual and heterosexual, and intensified sexual education from an early age, is in sympathy with our times, and although much is written on the problem which results, where is the essential missing chapter on prevention? The comment '. . . man can spend $\$ 120$ billion dollars to go to the moon and merely bring back some kilograms of rock, but mankind cannot devise a vaccine which eliminates gonorrhoea which last year infected at least 200 million people, or syphilis which infected 50 million' offers scant protection in the seventies.

R. R. Willcox

\title{
Notes
}

\section{The Society of Apothecaries of London}

\section{DIPLOMA IN VENEREOLOGY December 13 and 30, 1974}

The following candidates have satisfied the Examiners :

NASER ABDEL QADER HAJ-DEEB, B.Sc., M.B., B.Ch.Cairo.

JENNIFER PROVOST JONES, M.B., Ch.B.Edin.

ANIL RAMANLAL KAGALWALA, M.B.,

B.S.Bombay.

IBRAHIM AHMED MANTHY, L.M.S.E.Africa, D.T.M.\&H.

BARBARA LISCA MORGAN, M.B., B.S.Lond., M.R.C.S.Eng., L.R.C.P.Lond.

ISMAIL ABDUL-ROHMAN NOUR, M.B., B.Ch.Cairo.

JOHN DAVIDSON JOSEPH PARKER, M.B., B.Chir.Cantab., M.R.C.S.Eng., L.R.C.P.Lond.
SURESH PURSHOTTAM PATEL, M.B., B.S.Rajasthan.

CHELLAPPAH SHANMUGANATHAN, M.B., B.S.Ceylon.

SIAK KHIM TAN, M.B., B.S.Malaya.

CHAISIN VIRAVAN, M.D.Mahidol, D.T.M.\&H.

CHAVENGSAKSONGKRAM WITAYA,

M.D. Chulalongkorn.

YEE YEE, M.B., B.S.Mandalay.

ERNEST BusBY, M.B.E., L.M.S.S.A. (Hon.)

Registrar 